\title{
HISTÓRIA, MEMÓRIA E IDENTIDADE MARTINICANA EM O QUARTO SÉCULO DE ÈDOUARD GLISSANT
}

\section{HISTORY, MEMORY AND MARTINICAN IDENTITY IN FOURTH CENTURY BY ÈDOUARD GLISSANT}

Francisco de Assis Neto Universidade Federal do Tocantins, Araguaína, Tocantins, Brasil

Edna Sousa Cruz

Universidade Estadual da Região Tocantina do Maranhão, Imperatriz, Maranhão, Brasil

Resumo: Este artigo analisa o papel da história e memória no processo de recriação identitária dos antilhanos na obra $O$ Quarto Século, de Èdouard Glissant.

Palavras-chaves: Romance; História; Memória; Narrativa

Abstract: This article analyzes the role of history and memory in the process of identity reconstruction of Antilleans people, on the novel The Fourth Century by Edouard Glissant. Keywords: Novel; History; Memory; Narrative 


\section{Introdução}

O percurso que se desenvolve neste estudo segue a trilha do projeto literário desenvolvido pelo martinicano Édouard Glissant de (re)escrita da identidade (RAMOS JÚNIOR; MELO, 2013) do povo martinicano, desmitificando heróis, dando voz às minorias silenciadas pela história oficial, problematizando, por meio dos enredos, as consequências do processo de espoliação do sistema colonial europeu sob o qual muitos povos foram subjugados.

Tomando a literatura glissantiana como ação de resistência às consequências do colonialismo, neste artigo, analisa-se o romance $O$ Quarto Século, de Èdouard Glissant, a partir dessas premissas: de que a memória oral afrocentrada carrega em si toda uma subjetividade oriunda, primeiramente, da relação dos sujeitos com os fatos, e, em seguida, da forma como se constroem os discursos. Essa memória oral apresenta-se como matéria prima para a poetização da escrita da experiência histórica que intenta resgatar vestígios da experiência mental e corporal de dor e prazer por vezes distorcida, outras negada pelo discurso dominante.

Para Joutard (2007), a memória tem uma relação direta e ativa com o passado. Ela traz consigo uma carga de reconhecimento e reconstrução de episódios vividos, distanciados pelo passar do tempo, mas presentificados nas rememorações e nos produtos culturais que dela se originam: narrativas, artefatos, dentre outros. Procurar na memória trilhas de um passado que se faz presente implica, por vezes, re-transitar por terrenos tensos e conflitivo em que o falar do acontecido, conduz a uma nova percepção da condição do indivíduo e do episódio ocorrido. Walter (2008, p. 2), sustenta que

\footnotetext{
A memória somente pode conduzir à conscientização e resultante agir, a um conhecimento produtivo da condição do indivíduo, dentro do coletivo e das forças e práticas históricas e socioculturais que a ocasionaram, se as experiências individuais e coletivas estiverem entrelaçadas (WALTER, 2008, p. 2).
}

É somente na coletividade que o sujeito se afirma, e deste modo as lembranças (re)vividas por ele são tomadas como patrimônio articulado coletivamente por uma comunidade, quase sempre em um arquivo que forma os sistemas de enunciados a partir dos quais se organizam os acontecimentos.

Foucault, em Arqueologia do Saber (2007), pondera a respeito da noção de arquivo relacionado à memória, como um sistema de enunciados que engloba acontecimentos e coisas. Seriam os princípios que dão origem às situações históricas, enunciados que permitem compreender discursos e sua formação efetiva, caracterizando-se por uma composição que se organiza pela seleção de estruturas formais, assim como pela exclusão ou esquecimento de outras.

O arquivo é o espaço da escrita do passado pela memória e pela história. $\mathrm{O}$ enunciado, como parte do arquivo, é percebido como um fato singular a partir de possibilidades regidas pela noção de arquivo, pois este é que permite a articulação de enunciados que formam práticas discursivas, as quais ordenam sistemas de enunciados relacionados a acontecimentos ou coisas. Cabe, pois, perguntar: qual é relação da memória oral afro-centrada com o arquivo mormente instituído pelo colonizador?

A narrativa oral se organiza a partir da seleção de determinados enunciados e da exclusão e/ou esquecimento de outros. Assim como as narrativas escritas, as narrativas orais organizam um discurso relacionado a fatos passados em conformidade com a relação dos sujeitos com o fato histórico, com o modo como querem que esse fato seja rememorado. É 
importante ressaltar que a consciência histórica, ou seja, a compreensão de si como sujeito em relação com os fatos e com a sua historicidade, se configuram como o grande desafio daquelas sociedades que buscam compreender sua própria identidade e, a partir daí, configurar-se no tempo.

Nesse sentido a memória social, materializada em um arquivo democrático, exerce uma função de primordial importância nos processos históricos, a memória coletiva ao mesmo tempo que exerce o papel de guardiã dos objetos culturais (HALBWACHS, 1990), é também guardada por eles. Por seu intermédio os acontecimentos históricos portadores de significação para uma dada comunidade atravessam o tempo, vindo posteriormente se constituir em fonte historiográfica. Vale lembrar que não obstante ser tecida na coletividade, a memória é também um trabalho do sujeito, o qual toma forma a partir das comparações que ele faz entre suas experiências do passado e as atuais, através do diálogo com outros indivíduos que lhe permite confrontar diferentes pontos de vista.

A memória, por construir-se rizomaticamente enraizada a diferentes conjunturas, cenários, experiências e atores, reflete os múltiplos pertencimentos a que o indivíduo está submetido. Embora o termo memória remeta, à primeira vista, às ocorrências particularizadas, estas somente adquirem sentido e significado porque são, antes e originariamente, resultantes de uma coletividade. Este dualismo que perpassa a memória indicia que é na coletividade que o sujeito se afirma, e deste modo as lembranças (re)vividas por ele são tomadas como patrimônio articulado coletivamente pelo grupo.

Apesar de a memória parecer, a princípio, um fenômeno individual, de relação íntima, própria de cada um em sua individualidade, ela é, na verdade um fenômeno coletivo, "um fenômeno construído coletivamente e submetido a flutuações, transformações, mudanças constantes" (POLLAK, 1992, p. 202). Nesse sentido, o sujeito é histórica, social e culturalmente atravessado por todo um processo discursivo, imprimindo-lhe compreensões sobre sua própria identidade e posição no espaço em que vive.

Pollak (1992) observa que, apesar da característica flutuante e mutável da memória, em sua individualidade o no âmbito coletivo, há que se considerar o fato de que a memória ancora-se em marcos ou pontos mais ou menos invariáveis ou imutáveis. Isto significa que rememorar é sempre refazer, é flutuar e refletir, mas, sem dúvida, é manter pontos que servem de ancoragem, de marcos para a manutenção de uma história e da própria identidade.

Nesse sentido, compreende-se que numa história, tanto individual quanto coletiva, existem elementos irredutíveis, assim sendo por um trabalho de solidificação da memória. Em um certo ponto, esses elementos ou alguns deles ganham estatuto de realidade e passam a configurar a essência da pessoa. Alguns outros elementos que compõem uma história se modificam por causa da interação dos interlocutores, ou por causa do movimento da fala (POLLAK, 1992).

As considerações de Pollak (1992) são fundamentais para se pensar a forma como são construídas e mantidas as relações dos sujeitos com a sua própria história e como a relacionam com os outros sujeitos. Os fragmentos ou enunciados que estruturam o discurso de uma história são elementos com níveis de importância, conforme estejam em função da organização ou da manutenção da identidade. Há, portanto, um movimento de interação entre a oralidade/o discurso e a realidade assumida/vivida pelo sujeito, uma vez que o discurso está em função da organização de si, da individualidade, assim como da alteridade.

Pollak (1992) ainda observa que os elementos constitutivos da memória, tanto individual quanto coletiva, são oriundos, a priori, de experiências pessoais, de fatos vividos na 
individualidade. No entanto, a essa primeira categoria de elementos da memória se unem acontecimentos que o autor chama de "vividos por tabela". Estes são fatos do passado coletivo que o indivíduo possivelmente não viveu mas herdou como seus, fatos da socialização histórica/política em que o sujeito se projeta e se identifica com determinado passado.

O indivíduo é marcado, nesse sentido, pelo desejo de saber e manter um passado que o afeta enquanto sujeito social e cultural. Há, portanto, sentimentos que conduzem ao movimento de busca do conhecimento dos elementos do passado, os quais interferem no imaginário que organizam o próprio EU do indivíduo, assim como a sua relação com o todo histórico e social.

A história, por sua vez, como afirma Joutard (2007) inicialmente, instaura uma distância do acontecimento, porque na grande maioria dos casos, o historiador, vê o fato histórico de longe. Haja visto que o tempo histórico difere do tempo vivido, (MONTENEGRO, 1992), ele descreve e escreve sobre um passado não vivenciado.

Neste distanciamento temporal, diferente da memória, não há uma ligação afetiva com o acontecimento, ainda que este 'tenha alguma relação com sua própria história' (JOUTARD, 2007). Isto apontaria a impossibilidade da história de ser objetiva, ainda que assim ela queira ser. Le Goff em História e Memória (2003) citando Ricouer afirma que a história mantém uma estreita ligação com a imprecisão. Ela "quer fazer reviver e só pode reconstruir. Ela quer tomar as coisas contemporâneas, mas ao mesmo tempo tem de reconstituir a distância e a profundidade da lonjura histórica" (RICOEUR apud LE GOFF, 2003, p. 22). Sob esta perspectiva, a história é fruto de negociações e reconstruções representativas do acontecimento e, portanto, sujeita ao viés de que a escreve. A memória social, por outro lado, por ser fluída abre espaço para a diferença, para que as experiências e pontos de vista de diversos sujeitos emerjam.

\section{O Arquivo e a Diferença: história e memória em O Quarto Século}

Em O Quarto Século (1986), de autoria do antropólogo, poeta, romancista e pensador Édouard Glissant, a memória e história são vias de acesso ao passado. A memória é delineada por este romancista antilhano, como um documento vivo de experiências que se fundem na dor de narrá-las. Já a história, no romance, ocupa-se de desconstruir "o processo de dissimulação a que foi submetido o passado antilhano" (DAMATO, 1995 p. 174) ao ressiginificar no romance, por exemplo, figuras e acontecimentos da história da Martinica cujo valor foi gradativamente sendo esvaziado de seu sentido. Essa outra versão da história é inscrita no arquivo como versão afro-centrada da memória martinicana.

Glissant articula uma polarização entre duas situações: o que é memória e o que é história. No romance a memória está relacionada às questões de identidade que nos convidam a enveredar em uma narrativa de reconstrução histórica de um povo impedido, pelo processo de colonização, de construir uma imagem nítida do seu passado. Falamos da Martinica, cujo passado resta aos antilhanos apenas em resquícios, amarguras e sentimento de perda. Resta-lhes uma história estilhaçada pela prática de violência não apenas corporal, mas também mental e epistêmica.

Também conhecida como Ilha das Belas Flores, a Martinica situa-se nas Pequenas Antilhas ladeada pelas Américas do Norte e do Sul. Constituída a partir do ato colonial, nunca teve condições de exercer integralmente sua soberania (DAMATO, 1995). A Martinica só deixou de ser considerada colônia quando passou a fazer parte do departamento ultramarino da 
França. Contudo, ainda que tenha recentemente se desmembrado do domínio francês, o que significa maior autonomia administrativa, "ela nunca deixou de estar incorporada a outro país, nunca deixou de estar inserida numa outra história" (DAMATO, 1995, p. 173). Não obstante sua de possessão histórica e identitária, consequentes da ação da colonização, no que concerne à sua formação étnica e cultural, a Ilha Martinica pode ser entendida como espaço onde ocorre um processo de constante interação entre elementos diversos.

O romance $O$ Quarto Século (1986), assume o pesado exercício de reconstrução da composição da identidade martinicana, considerando o seu lugar enquanto parte da identidade caribenha e latino-americana, composta por fatos peculiares que imprimem características particulares àquele lugar. A reconstrução da identidade é dura porque se faz na opacidade da história. O que há são fragmentos dispersos dessa história, ou seja, enunciados separados que, por um movimento de reconstrução subjetiva, seleciona, relaciona, estrutura, apaga e constrói discursos.

Esta é a compreensão de historicidade marcada em Glissant, que aflora em $O$ Quarto Século, e que, neste artigo, busca-se demonstrar pela análise dos diálogos travados entre Papa Longuoé e o jovem Mathieu.

A historicidade, então, é um conceito ligado à ideia de arquivo de Foucault (2007), que, no caso do romance em foco, também se constrói pelo viés da narrativa escrita, isto é, encobre-se de uma linguagem significativa para a reflexão sobre a identidade do povo martinicano, mas que deve ser fecundada, segundo o autor, pela memória oral afrocentrada.

No nível da narrativa emerge, entre estes dois protagonistas, o jovem historiador, que após pesquisar em fontes documentais como livros e arquivos oficiais vai em busca de sua história, e um velho crioulo, que ao mesmo tempo que figura como guardião da memória de luta dos africanos e dos afrodescentes escravizados, atua também como verdadeiro arquivo do colonizado pela memória oral de que é portador.

A este respeito autores como Laroche (1991), Chamoiseau e Confiant (1991) ao discutirem o papel da "oralitura" como relevante objeto cultural, ressaltam a figura do contador como aquele que transmitia oralmente os contos e provérbios constituídos ao longo do tempo, como inscrição do imaginário. Segundo esses autores, o contador narrava, a partir de vestígios do passado, os sofrimentos dos seus antepassados escravizados, representando uma forma estética de resistência em que misturavam elementos de diversas culturas.

A trama do romance centraliza-se na formação das famílias de dois africanos que chegam à Martinica na condição de escravos, Loungoué e Beluse. Muito embora suas histórias estejam sempre se cruzando ao longo do enredo, seus destinos tomam rumos diferentes. Loungoué, alimentado pelo combustível do ódio guardado desde seu aprisionamento, após uma diversidade de embates com o homem branco contra sua nova situação, foge para as montanhas e lá constrói a linhagem dos Marrons. Beluse, tendo 'esquecido' seu ódio, torna-se escravo na plantação e tronco da família Béluse.

Os espaços pelos quais transitam Loungoué e Beluse, são determinantes na construção de novas identidades pois "[...] enquanto os negros da plantação recebiam os nomes dos senhores, os quilombolas escolhiam os seus nomes; as pessoas não os chamavam disto ou daquilo... Eles escolhiam e diziam e diziam a quem os cercava. Pronto meu nome é tal" (GLISSANT, 1986, p. 214). Nos encontros e desencontros destas duas linhagens, o velho e novo, o passado e o presente, a cultura popular e a erudita, se confrontam através dos diálogos entre o tradicionalista papai Longoué e o historiador ocidentalizado Mathieu os quais se lançam juntos numa longa interrogação do passado: 
- Conte-me o passado, papai Longoué! O que é o passado?

Desta vez, o quimboiseur não se deixou enganar pela aparência. Compreendeu muito bem que sob esta forma infantil a questão ia envolvê-lo totalmente. Que esta forma não era mais que uma última concessão que Mathieu quisera fazer-lhe, quando o garoto poderia ter-lhe perguntado apenas: "Que nos resta do passado?", ou, "Por que é preciso voltar ao passado?", ou fazer qualquer outro tipo de pergunta franca, clara sem rodeios. Não, ele tinha refletido sobre o modo de dizer aquilo (GLISSANT, 1986, p. 20).

O passado em $O$ Quarto Século é reinventado mediante a utilização de procedimentos que colocam em xeque a hegemonia da escrita, esta, motivo de orgulho dos ocidentais. Mathieu ao buscar definições sobre o passado se posta entre duas histórias: a história já vivida e a por ele pesquisada. No embate entre a história e a memória as "verdades" históricas de que Mathieu se considera conhecedor se diluem na narrativa de Lounguoe sobre a história dos escravizados e da violência da escravidão.

Eu te digo, Mathieu meu filho, ainda bem que você tem os livros para esquecer o detalhe, mas para saber o que se esquece: o cheiro por exemplo, a equipe da noite, e os imprevistos na habitação Senglis, o terreno que se transforma por toda a parte, os cães amestrados. Tudo isto te dá a explicação! Porque você nunca saberá o que custou cada um dos livros que você soletra de $a$ a $z$ (GLISSANT, 1986, p. 157).

Pela oralização da memória Papa Lounguoé reconstrói um lar dentro da linguagem imposta pelo colonizador, retifica as distorções e vazios da História oficial, a qual conta com o privilégio de diversos instrumentos documentais como fonte de conhecimento. A oralização da memória, resultante da depossessão linguística a que foram submetidos, instrumentaliza as personagens a recomporem por meio de rastros-resíduos suas línguas e manifestações artísticas.

Este termo caro para Glissant (2005), os rastros-resíduos estão relacionados a um pensamento assistemático e fragmentado, que traz em si a divagação do existente; que entrincheira a história por trás de obscuros retornos e aparentes reinícios, que agitam as incertezas daqueles que deram vida a ideia de História.

Nos rastros-resíduos da memória de papai Longoué, Mathieu inicia uma "pesquisa cuidadosa de reconhecimento daquilo que pode ser vestígio revelador do passado" (DAMATO, 1995, p. 174). Este trabalho de resgate torna-se desafiador porque implica refutar a história oficial, que ao impor sua versão dos fatos apaga os vestígios reveladores da história enquanto vivência que fundamenta o sentimento de pertença de Mathieu ao seu lugar. Com essa trajetória, o romance provoca uma reflexão em torno dessas interações enquanto deslocamentos, que rompem com uma concepção de fixidez e sedentarismo (ABDALA JUNIOR, 2002).

Sob esta perspectiva, cabe ao quimboiseur ${ }^{1}$ manter sempre viva na cotidianidade do seu povo a experiência da diáspora negra, como forma de mostrar que a história do negro somente na memória pode ser encontrada. Através da oralização da memória transmitida de geração em geração, assim como os questionamentos do jovem Mathieu e o posicionamento do velho Longuoé acerca da versão dominante da história apresentada como oficial, Glissant nos

\footnotetext{
${ }^{1}$ Quimbois, ou kenbwa, é o equivalente, para as Antilhas francesas, ao candomblé brasileiro. Papai Longouéé um representante dessa manifestação religiosa trazida pelos africanos à Martinica, como um "fragmento cultural" (GLISSANT, 1997). Em alguns momentos usaremos o termo quimboiseur para nos referirmos a essa personagem. Fonte: http://fr.wikipedia.org/wiki/Quimbois Acesso em: 12 dez. 2013.
} 
convida a pensar a memória, a "escavar o solo vermelho e desenterrar, no centro, a nascente do mar" (op. cit. 1986, p. 346), trazendo à tona o que está submerso.

A esse respeito, afirma Benjamin (2000, p. 239): "quem pretende se aproximar do próprio passado soterrado deve agir como um homem que escava". A disposição de Mathieu em escavar a história soterrada, em busca da recuperação de rastros residuais de um passado ofuscado e ocultado pela versão dominante, sinaliza, como alinhava a narrativa de papai Longoué, para a existência de uma multiplicidade de histórias e, portanto, possibilidades de outros itinerários de releituras das contradições históricas.

No romance, as brechas pelas quais os raios de luz penetram na obscuridade de uma história 'mal contada', efetiva-se através do diálogo entre o intelectual ocidentalizado Mathieu, e o intelectual da oralidade, o velho feiticeiro Longoué. Este transmite seus saberes através de uma memória que, dada a sua fluidez, não se ampara em suportes concretos, enquanto que aquele questiona tais saberes ancorado na História que se apoia nos documentos escritos.

O jovem Mathieu, ante a percepção de que os livros didáticos, registros e arquivos por ele consultados não lhe permite conhecer o passado de seu povo, haja vista o processo de exclusão que se dá pela escrita, "precisou buscar na memória dos velhos, no patrimônio oral negro, que funciona na obra como lugar onde as experiências silenciadas pela história escrita do colonizador podem ser encontrada, conhecidas e dadas a conhecer" (RAMOS; MELO, 2013, p. 23). O encontro entre a fluidez da memória e a (aparente) concretude da história acaba por se confrontar sendo tal embate materializado nos diálogos entre estes dois protagonistas:

Então! Você acha que um registro, um desses grandes cadernos que eles abrem na prefeitura no teu nariz para te impressionar, pode dizer porque um Béluse seguia assim um Longoué? [...] ou ainda como é possível que todas as línguas africanas tenham saído da cabeça deles como um voo de pardais? Abre os teus registros, bom você soletra as datas; mas eu tudo o que sei ler é o sol que desce como um grande vento sobre minha cabeça (GLISSANT,1986, p. 270).

O fragmento acima faz uma oposição entre duas concepções de história. O personagem do romance de Glissant opõe o que seria uma história oficial daquela que emerge das memórias dos que viveram os fatos a partir de um lugar de dominados em relação aos dominadores. Há uma menção a documentos registrados numa prefeitura e que poderiam ser utilizados para "impressionar", ou seja, para subjugar os indivíduos a partir de um registro que institucionaliza a história e rompe com quaisquer fragmentos de memória, com as parcelas que ainda possam restar do que foi o passado de violência e dominação.

O objetivo de Glissant em $O$ Quarto Século, como se vê no excerto anterior, é o de organizar uma poética em torno da proposição de que a história e a cultura fundam-se pela relação do homem com a natureza, isto é, com o seu espaço histórico, geográfico e político (mas eu tudo o que sei ler é o sol que desce como um grande vento sobre minha cabeça). As questões de identidade e cultura no romance estão intrinsecamente ligadas ao tráfico de africanos e à escravidão, fatos que transformam, marcam e identificam os sujeitos ali presentes. Propõe-se, por meio da narrativa, a reflexão sobre a não-relação dos homens com o espaço, com a história, com a própria língua. Isto é, há o enfoque no desapossamento do entorno original, da história e da língua de origem.

Portanto, a organização da literatura em Glissant se faz pela remissão às paisagens enquanto texturas e estruturas móveis. Em diversas partes de $O$ Quarto Século, o espaço aparece constituído de vários outros espaços despedaçados, aos quais se unem, de modo acumulativo, estilhaços de ambientes descritos por meio de uma mistura do exótico com o estranho, 
rizomaticamente ramificados. A linguagem da narrativa permite perceber esses espaços irrompendo de forma violenta, expostos por meio de um trabalho de gradação e soma da escrita e da clareza da intenção poética. Observa-se, claramente, uma relação interna com a paisagem, marcada sobremaneira pelo movimento, pela transformação, por jogos de luzes de sombra.

O movimento e a transformação violenta, marcada pelas estruturas da linguagem, remetem a um processo de desapropriação e imposição. Os contatos dos africanos recém chegados à América com o espaço e com os outros sujeitos subjugados são colocados no interior dessa dinâmica como elementos da transformação violenta, a partir da qual há o processo de perda das suas culturas originais (como é possível que todas as línguas africanas tenham saído da cabeça deles como um voo de pardais?) e de interação com outros povos e culturas, originando, inclusive a crioulização.

Em O Quarto Século, este processo de crioulização, dá-se, não apenas a partir da junção de elementos culturais, mas, também, pela privação deles. Despojados de toda espécie de referenciais de sua identidade, os africanos Longoué e Béluse, chegam 'nus' à nova terra. Esses migrantes africanos

Chegam despojados de tudo, de toda e qualquer possibilidade, e mesmo despojados de sua língua. Porque o ventre do navio negreiro e o lugar e o momento em que as línguas africanas desaparecem, porque nunca se colocavam juntas no navio negreiro, nem nas plantações, pessoas que falavam a mesma língua. O ser se encontrava dessa maneira despojado de toda espécie de elementos de sua vida cotidiana, e, sobretudo de sua língua (GLISSANT, 2005, p. 19).

Mathieu e Papai Longué são, no entender de Martins (2006), frutos de uma transculturação positiva, posto que não há adaptação passiva de um na cultura do outro. A postura dos dois protagonistas é pautada por um processo no qual tanto a cultura que tenta se impor como a que luta para não se subjugar sofrem transformações. Enquanto esses protagonistas veem-se envolvidos num jogo de negociações culturais, Fernando Ortiz (1978) ressalta que o processo de transculturação, também envolve todo um jogo de dominação e imposição. Para esse estudioso, esse processo se daria, primeiro, numa desculturação, em que o povo dominado sofre perdas de componentes de sua cultura; seguindo-se a incorporação da cultura externa imposta, que culmina numa neoculturação, isto é, a articulação de elementos culturais primitivos a elementos externos contraídos.

Ortiz (1978) justifica sua tese dizendo que não há, no Caribe, uma estrutura formada por dois povos em que uma única cultura influi sobre as outras. Há, na verdade, uma reunião de povos marcada por várias ondas migratórias, que reuniu, de modo livre ou não, negros de diversas nações africanas a povos indígenas, portugueses, espanhóis, franceses, judeus, chineses etc. Nesse encontro, não há hegemonia de um sobre o outro, no sentido de que todos, ao saírem de suas terras de origem, passaram pelo processo de distanciamento de uma cultura original, substituindo-a por uma nova formação.

O encontro, o choque, a imposição e a crioulização fazem parte desse processo que modifica os sujeitos e os coloca em contato com o novo espaço, envolvendo aí as questões culturais, históricas e geopolíticas. Daí a importância de uma estrutura da linguagem que põe em movimento violento, de modo dinâmico, essa interação dos sujeitos com o ambiente e de uns com os outros. Se por um lado, houve uma imposição para o apagamento da memória, por meio, inclusive, de registros oficiais em documentos guardados pelos dominadores, por outro, há a ativação da memória, que ocorre pela junção dos fragmentos de uma história oral com a relação dos homens com a natureza. 
A natureza, por conservar marcas do passado, é um elemento fundamental na ativação da memória. O vento, de modo particular, é a memória em movimento, trazendo para a superfície "a invisível floração desta cepa humana" (GLISSANT, 1986, p. 58). Ao mover-se continuamente, vestindo o sujeito com sua brisa envolvente este elemento também reacende, de geração em geração, a lembrança sensorial, do odor do navio negreiro, da escravidão, da morte, e igualmente aquela da resistência, dos bosques, da vida e do sofrimento. O vento é a oralização da memória que estabelece a continuidade entre o passado e o presente nos diálogos entre Papai Longué e Mathieu.

Todo este vento, disse papai Longoué, todo este vento que está para subir, você não pode fazer nada, espera que ele suba até as tuas mãos, e depois à boca, aos olhos, à cabeça. Como se um homem existisse apenas para esperar o vento, para se afogar, sim, você está ouvindo, para se afogar de uma vez em todo este vento como no mar sem fim (Id. Ibid. p. 15).

No ambiente natural de $O$ Quarto Século, a paisagem apresenta-se como portadora de uma linguagem que evidencia o seu valor na formação cultural e identitária da Martinica. De modo figurativo, as imagens e representações que ela evoca retratam os vestígios de uma memória e identidade coletivamente construídas. O mar por exemplo, figura como a tumba dos escravizados que eram lançados 'como para dragar o fundo ou como para tomar a posição e calcular a profundidade' (GLISSANT, 1986, p. 27).

Os saberes do velho quimboiseur acerca do oficio de feiticeiro são originários não apenas daqueles que vieram da África, mas também de várias outras fontes, tais conhecimentos são reelaborados à medida que são propagados no espaço antilhano. Retomando a transculturação positiva dos protagonistas sustentada por Martins (2006, p.106), vemos que o relato descontínuo e incisivo de papai Longoué "emancipa Mathieu, que carregava o legado cultural ocidental sob forma de uma leitura unilateral e alienante. Ajuda-o a refletir que a cronologia imposta pelo colonizador e a sua visão eurocêntrica não podem ser ponto de referência para a reconstrução da memória colectiva [sic!]”. Apesar do seu descrédito inicial acerca da versão do feiticeiro sobre a história de seu povo, Mathieu gradativamente começa a ver a realidade com lentes diferentes das habituais, e a partir deste novo olhar ele começa também a entender que é só escavando o passado, para revivê-lo e compreendê-lo que alguém poderá entender o presente.

\section{Considerações finais}

Em O Quarto Século, Edouard Glissant reforça a importância de se considerar a memória oral afrcentrada como elemento de construção do arquivo histórico no mesmo patamar que outros documentos já validados pela Ciência, posto seu papel de resgatar a voz do próprio sujeito inserido no processo, na cultura, ao presentificar um passado tenso e conflitivo, perturbado por um processo histórico de exploração e imposição do discurso externo.

O romancista Glissant, ao utilizar da linguagem literária impregnada em sua veia de romancista, aproxima-se das discussões dos autores transculturais da América Latina, com vistas a reconstruir a experiência da diáspora negra na Martinica através de uma narrativa que ressalta a importância da memória oral afrocentrada, como elemento norteador do caminho que levaria às trilhas do passado do povo antilhano mesmo que de modo fragmentado e desordenado. 
O esforço do autor por construir uma narrativa que reúna diversos elementos tão próprios da Martinica afigura-se tentativa de ao articular a memória oral, catalisar identidade, resulta numa mostra do que o autor concebe como meio possível e único para se conhecer, o passado e o presente dos os martinicanos e caribenhos.

\section{Referências}

ABDALA JUNIOR, B. Fronteiras múltiplas, identidades plurais. São Paulo: Ed. Senac, 2002.

BENJAMIN, W. Imagens de Pensamento. In: BENJAMIN, W. Rua de mão única. Tradução de Rubens Rodrigues Torres Filho e José Carlos Barbosa, 5. ed., São Paulo: Editora Brasiliense, 2000, 278p.

CHAMOISEAU, P.; CONFIANT, R. Lettres creoles. Paris: Hatier, 1991.

DAMATO, D. B. Edouard Glissant: poética e política. São Paulo: AnnaBlume, 1995.

FOUCAULT, M. Arqueologia do saber. Tradução de Luiz Felipe Baeta Neves. Rio de Janeiro: Forense Universitária, 2007.

GLISSANT, E. O Quarto Século. Tradução de Cleoné Augusto Rodrigues. Rio de Janeiro: Guanabara, 1986.

GLISSANT, E. Traité du Tout-Monde. Paris: Gallimard, 1997.

GLISSANT, E. Introdução a uma poética da diversidade. Tradução de Enilce do Carmo Albergaria Roch. Juiz de Fora: Editora UFJF, 2005.

HALBWACHS. M. A memória coletiva. Tradução de Laurent Léon Schaffter. São Paulo: Revista dos Tribunais, 1990.

JOURTARD, P. Reconciliar história e memória? Escritos Um: Revista da Casa de Rui Barbosa, ano 1, n. 1, 2007.

LAROCHE, M. La double scène de la représentation. Oraliture et littérature dans la Caraïbe. Québec: GRELCA, coll. Essais, n. 8, Université de Laval, 1991.

LE GOFF, Jacques. História e memória. Tradução de Bernardo Leitão. Campinas: Editora da Unicamp, 2003.

MARTINS, C. O entrelaçar de vozes mestiças. Análise das poéticas da alteridade na ficção de Edouard Glissant e Mia Couto. Principa Editora: Estoril, 2006.

MONTENEGRO, A. T. História oral e memória: a cultura popular revisitada. São Paulo: Contexto, 1992. 
ORTIZ, F. Contrapunteo cubano del tabaco y el azúcar. Caracas: Biblioteca Ayacucho, 1978.

POLLAK, M. Memória e identidade social. Estudos Históricos, v. 5, n. 10, p. 200-212, 1992.

RAMA, A. Os processos de transculturação na narrativa latino-americana. In: AGUIAR, F.; VASCONCELOS, A. R. (orgs.). Literatura e cultura na América Latina. São Paulo: Edusp, 2001, p. 209-239.

RAMOS JÚNIOR, D. V.; MELO, M. A. Edouard Glissant e a narrativa da descolonização. Revista Mosaico, v. 6, n. 1, p. 17-23, 2013.

WALTER, R. Tecendo identidade, tecendo cultura: os fios da memória na literatura afrodescendente das Américas. XI Congresso Internacional da ABRALIC. Tessituras, Interações, Convergências. Julho de 2008. USP - São Paulo, Brasil.

Recebido em: 12 de julho de 2020 Aceito em: 16 de novembro de 2020 Publicado em dezembro de 2020 